
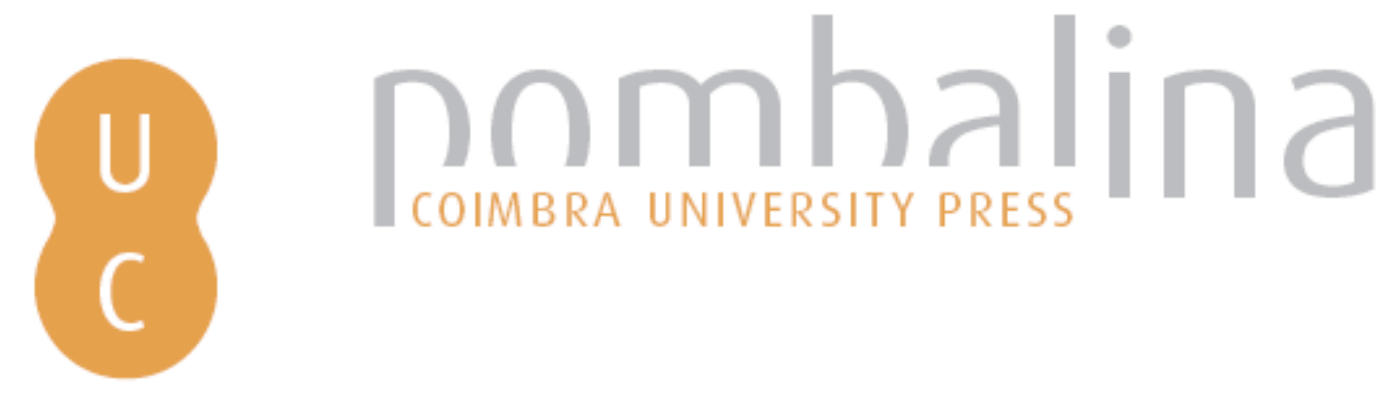

\title{
Revisitar o itinerário raiano do Prof. Gama Mendes através de uma visão geográfica
}

Autor(es): $\quad$ Castro, Emanuel de

Publicado por: Imprensa da Universidade de Coimbra

URL

persistente: URI:http://hdl.handle.net/10316.2/43496

DOI: $\quad$ DOI:https://doi.org/10.14195/978-989-26-1343-7_26

Accessed : $\quad$ 26-Apr-2023 08:51:11

A navegação consulta e descarregamento dos títulos inseridos nas Bibliotecas Digitais UC Digitalis, UC Pombalina e UC Impactum, pressupõem a aceitação plena e sem reservas dos Termos e Condições de Uso destas Bibliotecas Digitais, disponíveis em https://digitalis.uc.pt/pt-pt/termos.

Conforme exposto nos referidos Termos e Condições de Uso, o descarregamento de títulos de acesso restrito requer uma licença válida de autorização devendo o utilizador aceder ao(s) documento(s) a partir de um endereço de IP da instituição detentora da supramencionada licença.

Ao utilizador é apenas permitido o descarregamento para uso pessoal, pelo que o emprego do(s) título(s) descarregado(s) para outro fim, designadamente comercial, carece de autorização do respetivo autor ou editor da obra.

Na medida em que todas as obras da UC Digitalis se encontram protegidas pelo Código do Direito de Autor e Direitos Conexos e demais legislação aplicável, toda a cópia, parcial ou total, deste documento, nos casos em que é legalmente admitida, deverá conter ou fazer-se acompanhar por este aviso.

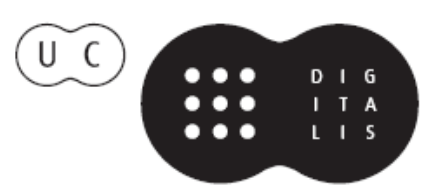




\section{FERNANDA CRAVIDÃO}

\section{IÚCIO CUNHA}

PAULA SANTANA

\section{NORBERTOSANTOS}

(ORG.)

\section{ESPAÇOS E TEMPOS EM GEOGRAFIA}

HOMENAGEM A ANTÓNIO GAMA

IMPRENISA DÁ UNIVERSIDADE DE COIMBRA COIMBRA UNIVERSITY PRESS

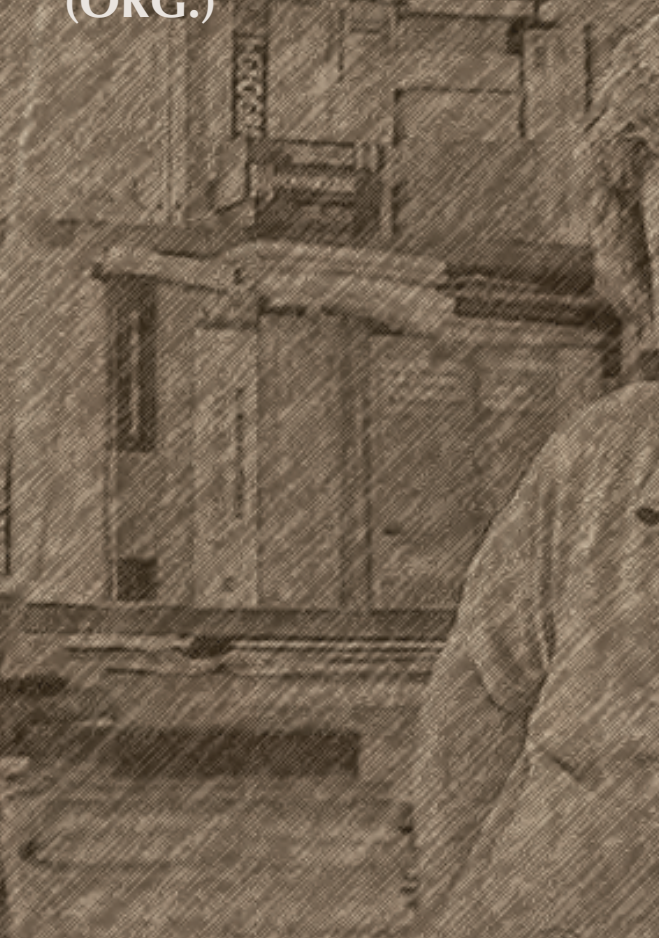




\title{
REVISITAR O ITINERÁRIO RAIANO \\ DO PROF. GAMA MENDES \\ ATRAVÉS dE UMA VISÃO GEOGRÁFICA
}

\author{
Emanuel de Castro/emanuelcastro@ipg.pt \\ Ana Lopes \\ Instituto Politécnico da Guarda
}

\section{Introdução}

A fronteira surge no léxico geográfico como algo que divide dois territórios, duas dimensôes espaciais, duas culturas ou, simplesmente, o final e início de qualquer parcela geoespacial. Todavia, mais do que uma terminação geográfica, a fronteira tem assumido um significado conceptual, recorrentemente discutido e analisado, nem sempre pelas melhores razóes.

A raia portuguesa em geral e a da Região Centro em particular apresenta um conjunto de vulnerabilidades que a história se encarregou de construir e o presente não soube ultrapassar. A sua baixa densidade marca o quotidiano destes territórios, pesem embora alguns esforços em sentido contrário, mesmo que para muitos, ainda tímidos. No espaço e no tempo têm sido identificados alguns problemas estruturais que decorrem, em larga medida, da escassa população existente, resultante quer do êxodo rural, quer da emigração em diferentes momentos do século xx e início do atual. Na verdade, a ausência de dinâmicas demográficas póe em causa quaisquer estratégias de desenvolvimento, por muito profícuas que possam parecer. Partindo deste cenário, torna-se necessário que 
se altere a narrativa vigente. Da compreensão da sua história devemos saber construir o futuro, das vulnerabilidades devemos fomentar as dinâmicas de desenvolvimento. Ancorada numa paisagem ímpar de significado, quer pela sua história, quer pela estrutura organizacional que apresenta, a fronteira deve ser hoje objeto de requalificaçáo, repensando o modo como a podemos viver e desenvolver. Muitas são as oportunidades que se identificam nestes espaços que, ao contrário do que alguns fazem acreditar, não se esgota nas práticas turísticas. $\mathrm{Na}$ verdade, acreditamos na importância do turismo para a promoção destes espaços, desde que integrado em estratégias holísticas, assentes na dinamização do tecido produtivo e no seu potencial endógeno.

Através da sua refuncionalização, torna-se premente que estes territórios não vivam apenas na memória da sua história, mas possam continuar a construir o seu presente, deixando marcas para que outros, no futuro, as transformem em identidade. Neste contexto, a patrimonialização de alguns valores territoriais e comunitários constitui um reforço da sua identidade, representa um fator de pertença para as suas comunidades e pode induzir outras práticas e dinâmicas. $\mathrm{Se}$, na verdade, estes territórios de fronteira já não são o que eram, devem trabalhar para que hoje, tal como amanhá, possam ser outra coisa. Dito por outras palavras, é premente que os espaços de fronteira sejam reconhecidos e percebidos como territórios de esperança, não apenas cenário bucólico de um país à beira-mar plantado. Mas acima de tudo, como parte de uma geografia muito mais importante que os seus limites. Um território cuja relação com as regiôes espanholas deve ser trabalhada como uma oportunidade, um desafio e, sobretudo, uma inevitabilidade.

\section{A paisagem raiana: da sua geografia à patrimonializaçáo}

A paisagem é constituída por um conjunto de elementos, dos quais fazem parte os processos naturais e a utilizaçáo que deles fazem os grupos humanos, apresentando uma determinada organização e estrutura espacial. Qualquer uma das componentes existentes apresenta uma clara dependência em relaçáo a um 
todo, resultando sempre da sua interaçáo no tempo e no espaço. Desta forma, é a materialização das componentes físicas e humanas que reveste de sentido aquilo que chamamos paisagem e que constitui, no fundo, o território, objeto de estudo "caro" à Geografia. Os estudos da paisagem pressupóem, antes de mais, a procura da identidade ou identidades de um território, em função do seu genius loci, assente numa nova visão ecológica, perspetivando não só os atuais usos, mas acima de tudo, o planeamento dos futuros. Não nos podemos esquecer que a paisagem, entendida na perspetiva das ciências que a estudam e da sua aplicabilidade, é muito mais do que o vocábulo português significa; "[...] porção de território que abrange num lance de olhos; vista; panorama; [...]” (Dicionário de Língua Portuguesa da Poro Editora, 2006). Mas é também tudo isto.

A Paisagem raiana constitui um território complexo a nível social, económico e demográfico, mas com um carácter bem vincado, no qual se evidenciam os elementos naturais que a constituem. De facto, destaca-se, neste território, a riqueza e a variedade da paisagem, entendida sobretudo como um complexo sistema de factos e de valores, originados essencialmente pelo contexto evolutivo destes territórios. Apesar de não se poder falar, exclusivamente, em paisagens naturais, de facto, são os elementos da natureza (morfologia, água, vegetação) aqueles que mais valorizam esta paisagem (Cunha, 1995).

Neste território raiano podemos individualizar parte da superfície da Meseta (superfície de aplanamento poligénica), com significativa conservação a Este do rio Côa, onde podemos encontrar alguns relevos residuais de elevado interesse geomorfológico e paisagístico (Serra da Marofa). Por outro lado, parece-nos importante perceber os contrastes na paisagem entre a área da Meseta (com notável inclinação entre o sopé da Serra da Malcata, com altitudes que rondam os 950-1000 metros, e a Norte com uma altitude de 400-450 metros), os relevos mais acidentados da Serra da Malcata, área de transiçáo entre a Meseta e a Superfície de Castelo Branco, que pelos 400-500 metros de cota revela já uma aproximação às paisagens do Sul do País, bem testemunhada pela presença de montados de azinho e mesmo de sobreiro (Ribeiro, 1949 cit. por Cunha, 1995). 
Do conjunto dos relevos aplanados, da referida superfície, emergem importantes elementos que marcam a paisagem. Assim, a favor do carácter granítico do substrato e de uma evoluçáo muito longa e particular, os chamados inselberge, dos quais se pode destacar Monsanto, mas também o de Belmonte ou de Linhares da Beira. Para Sul desta superfície encontramos a "Superfície do Alto Alentejo" aqui conhecida pela designação geral de "Campinas da Idanha”, através da vigorosa escarpa que marca a passagem da falha do Ponsul (Idem). Aqui a paisagem adquire um novo carácter, fruto não só dos novos contrastes geomorfológicos, mas também da própria ocupação e atividade humana.

A imponência dos relevos da raia central marca, de modo contundente, a paisagem visual. Estes elementos conferem um carácter vigoroso aos trechos de montanha que dominam vastos setores da nossa área de estudo. Assim, tanto as Serras da Cordilheira Central (Serra da Estrela e da Gardunha) como a Serra da Malcata ou as vigorosas Serras quartzíticas da Marofa, Penha Garcia ou do Ródão quebram a monotonia dos relevos aplanados, constituindo o fator mais importante para a caracterização daquelas unidades paisagísticas. Entre as Serras da Estrela e Gardunha, devido à tectónica de fraturação existente, surge-nos um fosso de separaçáo conhecido como a Cova da Beira, que apresenta características climáticas particulares, característica que se revela na própria atividade humana presente.

Paralelamente a estes elementos morfológicos, fruto da história tectónica e orogénica, encontram-se os vales, indissociáveis do quadro paisagístico da raia central. Estas formas, muitas vezes profundamente encaixadas, constituem espaços de natural beleza e de importante valor em termos ambientais, como acontece com o Côa, o Águeda e o Douro, a Norte, e com o Tejo e os seus afluentes, o Erges e o Ponsul, a Sul.

A Raia Central, tal como suprarreferido, apresenta uma variedade de elementos paisagísticos que merecem uma atençáo especial, do ponto de vista da sua valorização e do seu aproveitamento. Os fatores históricos, as condiçôes sociais e culturais, os aspetos naturais e a ocupaçáo do espaço, associada às tradiçôes e modos de vida das populaçôes muito particulares, são fatores suficientes para 
não deixarmos de falar da sua patrimonialização e do papel que pode ter na revitalização destes setores.

A paisagem será, então, um meio através do qual se constrói a identidade de um lugar, surgindo tanto como uma representação (um ideal que revela sentido), como uma existência material (a realidade das condiçóes de vida) (Harner, 2001). Aqui reside um outro problema das paisagens raianas, as condiçôes de vida das suas populaçóes e a ausência de outros recursos que permitam o seu desenvolvimento. Com o declínio demográfico, o despovoamento e abandono de um conjunto de práticas tradicionais, restam alguns nichos ou retratos daquilo que a paisagem havia sido. As políticas de valorização devem começar precisamente pela fixação das populaçóes e a melhoria das suas condições de vida, uma vez que a ideia de indução de atividades como o turismo não resulta da mesma forma em todos os territórios. As preocupaçóes sobre a questão da transformação da paisagem como componente da identidade territorial e da sustentabilidade na era atual de globalização económica e cultural, ganhou maior relevância na última década, tanto ao nível da investigação sobre as problemáticas do desenvolvimento, como ao nível das agendas políticas, sobretudo quando aquelas preocupaçóes têm por objeto as áreas rurais ou periféricas e em processo de desvitalização social e económica (Roca e Oliveira, 2004).

A imagem dos territórios está, intrinsecamente, relacionada com a sua paisagem, não apenas com aquilo que a nossa visão alcança, mas todos os elementos que a compóem e que lhe dão "vida", cheiro e cor à sua dimensão espacial. Estas imagens que se constroem e que dão forma e conteúdo aos lugares estão, muitas vezes, associadas à qualidade ambiental de inúmeros setores da raia, à diversidade e heterogeneidade das suas paisagens, à sucessão de elementos patrimoniais. Tanto histórico-culturais como naturais, aos modos de vida ligados às práticas tradicionais, materializadas em alguns produtos regionais, tradiçóes e outros "usos", aos recursos naturais de valor estratégico, alguns com potencial energético, e à história da história das gentes de cada lugar. Todos estes fatores, de ordem natural, social, cultural e histórica podem e devem ser aproveitados, em primeiro lugar pela fixação da população, condição sine qua non para o tão almejado dinamismo dos territórios. 


\section{O itinerário raiano do professor Gama Mendes}

As características geográficas da fronteira raiana entre o Douro e a Cordilheira Central evidenciam um conjunto de fatores comuns, dos quais destacamos uma área de fronteira territorialmente marginal (povoamento, demografia, economia e estruturação espacial); os problemas comuns às áreas marginais (fragilidade económica e marginalidade social) e a cooperação e conflitos dos mesmos (nomeadamente a questão das bacias hidrográficas internacionais e as redes de transportes).

A Raia, com mais de setecentos anos em que ambas as sociedades têm estado, em boa parte, de costas voltadas, emergiu do avanço do repovoamento que, durante os primeiros tempos dos reinos cristãos medievais da península, se foi produzindo. Até que no século XIX se dão os últimos retoques nos seus limites, tornando-se assim uma fronteira histórica, cuja geografia se apoia na maior parte do seu traçado em cursos fluviais, ainda que, longe de constituir um limite natural absoluto, passou a ser uma das fronteiras mais estáveis e, por isso, uma perfeita divisória de povos e culturas que acabaram por vir a diferenciar, de forma continuada, os dois Estados Ibéricos, criando uma zona fronteiriça a que se vem designando por raia.

Este espaço é o protótipo de um território extenso (1232km de comprimento e aproximadamente $150000 \mathrm{~km}^{2}$ de espaços fronteiriços abarcando dez distritos e sete províncias vizinhas) ao mesmo tempo marginal e periférico (com uma densidade populacional reduzida e índices de industrialização e de urbanização baixa, em relação às médias quer nacionais, quer comunitárias). Por outro lado, ainda que a raia não tenha contrastes importantes ou disparidades sociodemográficas, económicas, e de infraestruturas entre uma e outra margem da fronteira, existem algumas diferenças no grau de urbanização, de desenvolvimento económico, com evidentes desvantagens para Portugal. Esta é a fronteira do subdesenvolvimento, que ocupa uma boa parte do que foi a regiáo romana da Lusitânia, com amplos vazios de serras e de montado ou de matagal e uma mínima presença de cidades, uns poucos corredores e reduzidos fluxos viários entre um lado e outro, sendo em grande medida áreas terminais 
e não intermédias dos sistemas urbanos e mercados nacionais. Esta regiáo de fronteira, apesar da sua contiguidade, tem tido até agora muito pouca interpenetração, até que, depois de ambos os estados se incorporarem na Comunidade Europeia, o processo de inter-relaçóes e cooperação, ao menos ao nível inter-regional e internacional (turistas, capitais e empresas) está a mudar a situação herdada, de marginalização e de subdesenvolvimento, geralmente conhecida como "síndroma da raia".

Envolvendo os distritos de Bragança (nomeadamente os concelhos de Miranda do Douro, Mogadouro e Freixo de Espada à Cinta) e Guarda (concelhos de Figueira de Castelo Rodrigo, Almeida e Sabugal) pela parte portuguesa e as províncias de Zamora (nomeadamente as comarcas de Aliste e de Sayago) e de Salamanca (comarcas de Vitigudino e Ciudad Rodrigo) pela parte espanhola, o itinerário raiano do Professor Gama Mendes pretende demonstrar esta realidade, de um lado e do outro da fronteira, quer ao nível da ocupação do espaço, quer na ótica da gestão do Património Construído e Natural.

O percurso (Figura 1) corresponde ao setor Norte das terras de Riba-Côa, começando em Castelo Mendo, fortaleza na antiga linha de fronteira anterior ao tratado de Alcanices (1297). Passando o Rio Côa pela estrada antiga, dirigimo-nos para Castelo Bom (Figura 2), que ficava do outro lado da fronteira, em domínio castelhano, com destino a Vilar Formoso (Figura 3), povoação de passagem da fronteira atual. Em seguida, visitamos duas obras de arte militar dos tempos modernos, de estrutura abaluartada, uma em tempos abandonada, Fuerte de la Concepción (atualmente refuncionalizada em Hotel Rural - Figura 4) e outra sede de concelho, Almeida (Figura 5). Todo o restante percurso se faz ao longo da raia, com especial atenção para as povoaçóes de fronteira que espelham o seu quotidiano (Figura 6). 


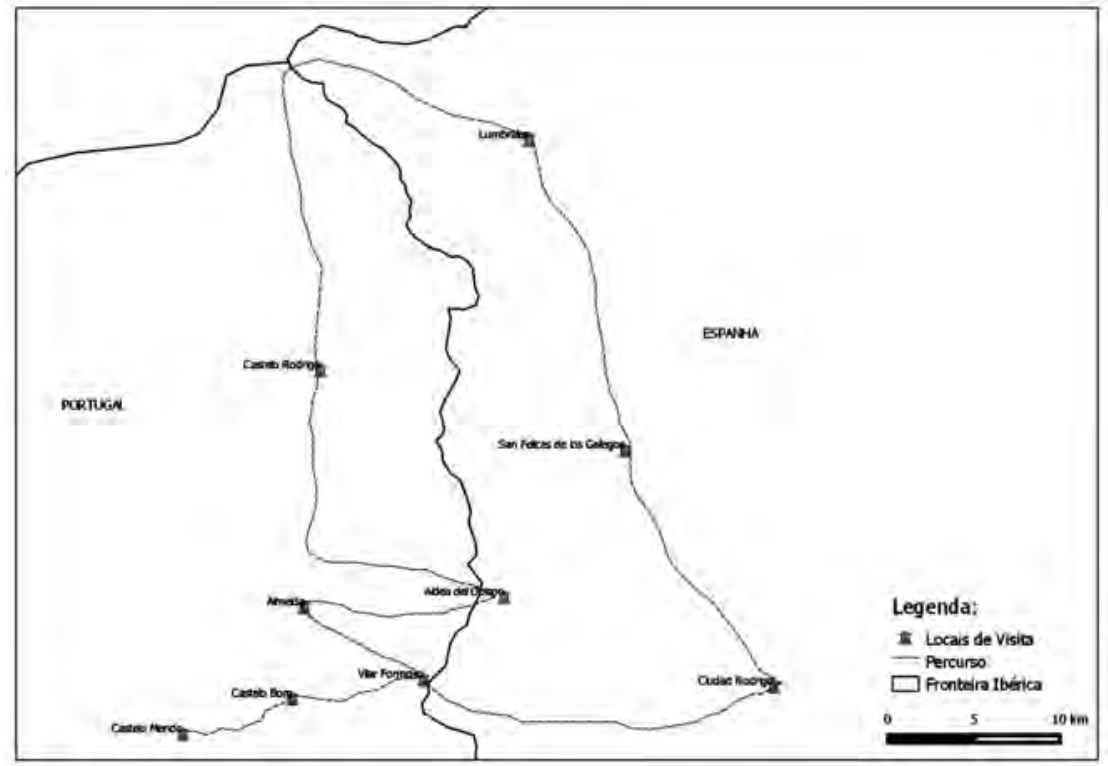

Figura 1

Representação esquemática do Itinerário Raiano do Professor Gama Mendes

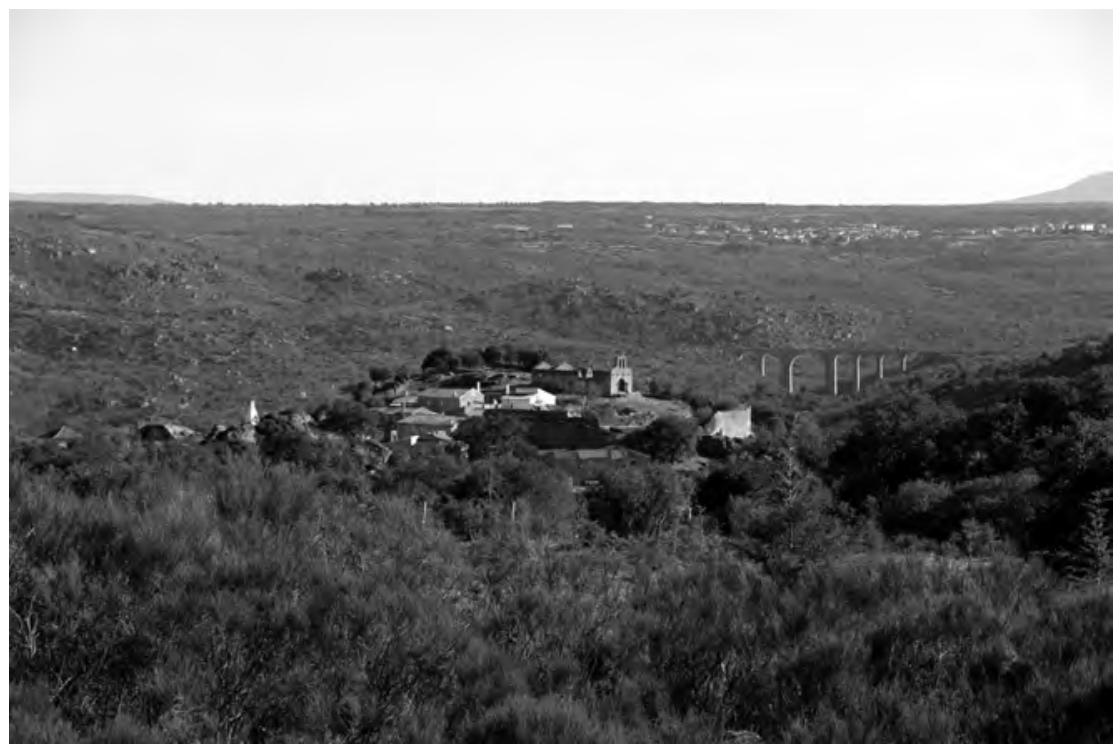

Figura 2

Vista panorâmica de Castelo Bom 


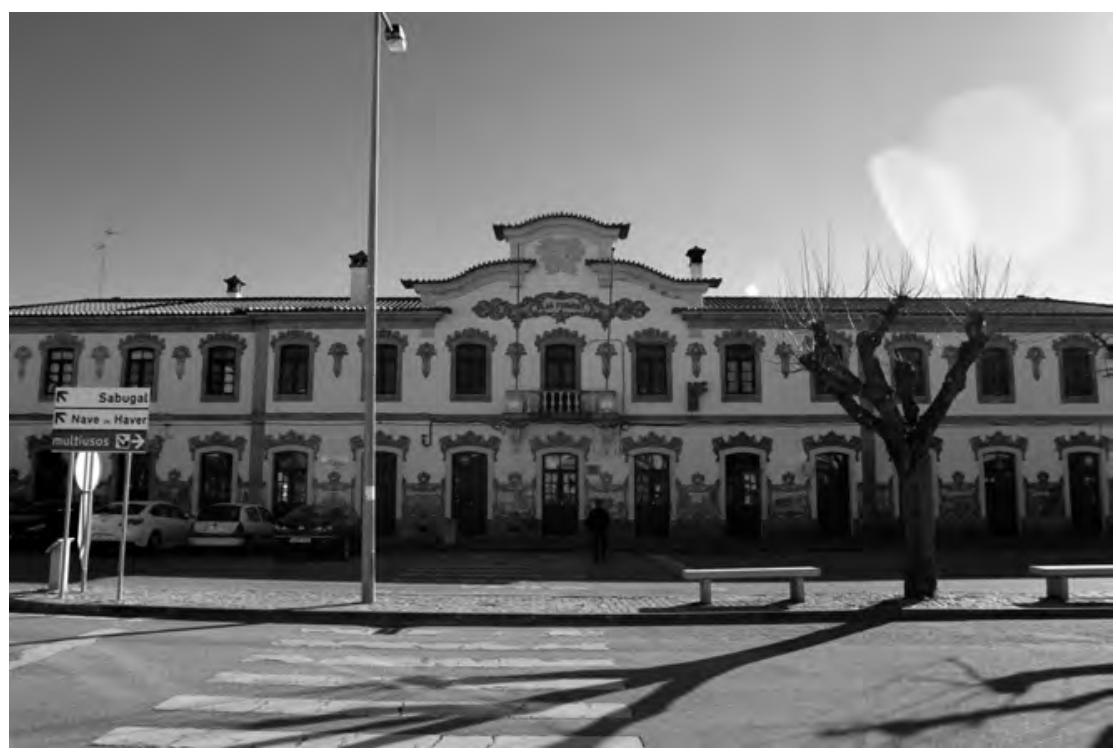

Figura 3

Estação ferroviária de Vilar Formoso, exemplo de património azulejar civil

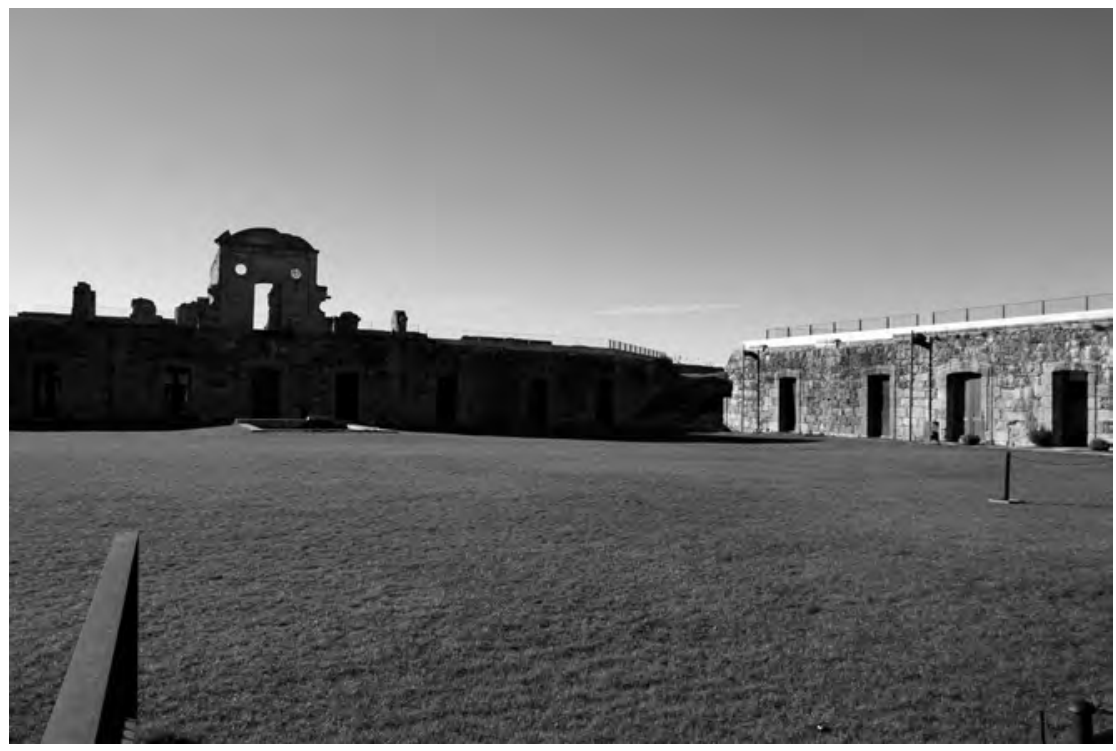

Figura 4

Antigo Fuerte de la Concepción, agora refuncinalizado em Hotel Rural 


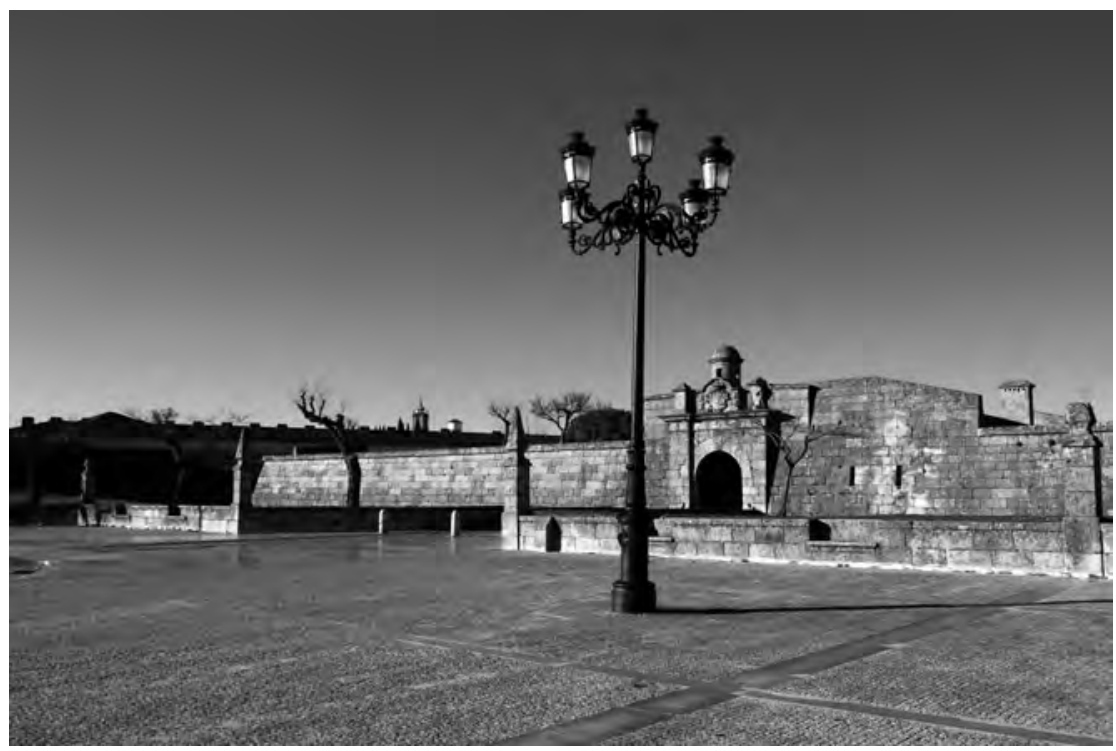

Figura 5

Entrada Poente do Forte de Almeida

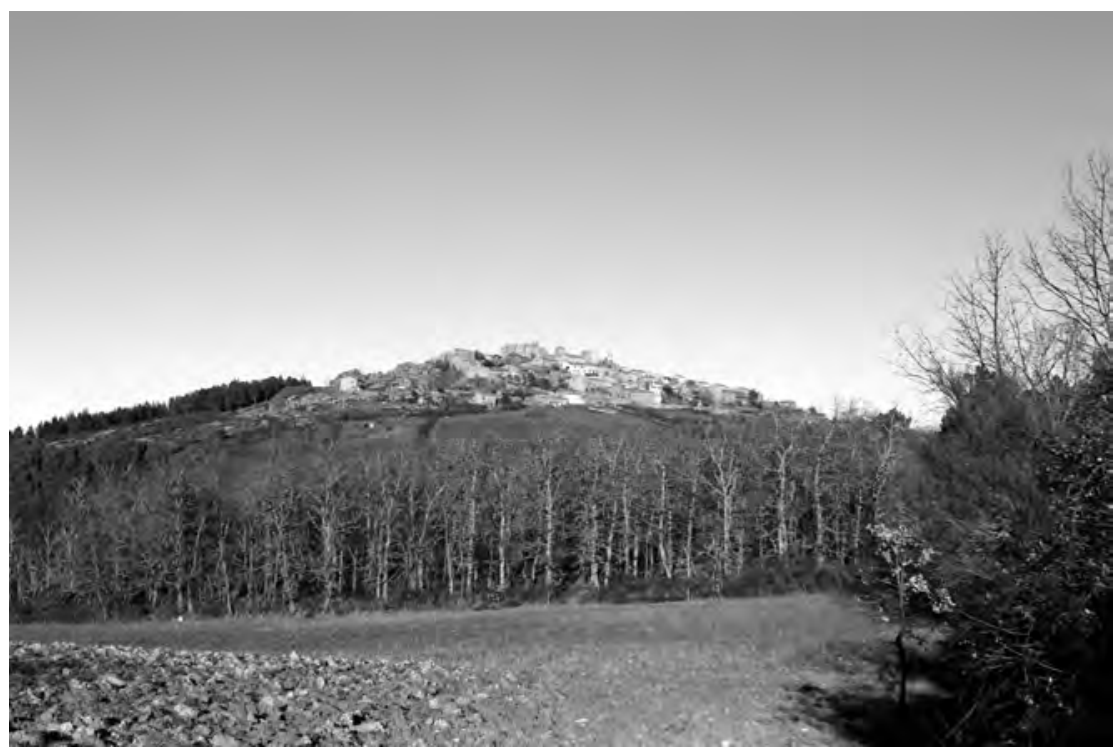

Figura 6

Vista panorâmica da Aldeia Histórica de Castelo Rodrigo 


\section{Notas finais}

Com o advento das sociedades modernas, industrializadas e seculares, e com o consequente afastamento relativamente às anteriores modalidades de filiação, o património surge como um artifício criado no sentido de fortalecimento de uma pertença a um espaço simbólico que faz parte integrante do processo evolutivo das sociedades. Podemos considerar, entáo, que o património surge como uma intervenção, uma construçáo mental da modernidade. Ao mesmo tempo que se atribui uma transcendência a determinados símbolos culturais que atestam um carácter singular de uma determinada comunidade, conferindo uma ilusão de permanência e continuidade em relaçáo a um passado, construindo-se um ideal coletivo para o futuro. Esta valorizaçáo social do património fez com que progressivamente se desenvolvessem açóes conducentes à reativação do património, protagonizadas por vários agentes locais, com vista à sua rentabilizaçáo económica mediante a promoção local e regional e a captaçáo de fluxos turísticos, com o objetivo último de dinamizar os territórios, tendo por base eles mesmos e as marcas antrópicas veiculadas através da sua geografia.

Contudo, este desenvolvimento suportado pela patrimonialização, só será plenamente alcançado se contar com a participação de todos os intervenientes do território, bem como com uma análise integrada do mesmo através da identificação das suas fragilidades e das potencialidades existentes.

Este olhar atento das sucessivas transformaçóes geográficas e sociais da paisagem raiana esteve presente em todas as saídas de campo do Professor Gama Mendes, nas quais tivemos o privilégio de participar. Mais do que uma visita, constituiu um marco na nossa formaçáo como geógrafos, mas sobretudo, enquanto pessoas!

\section{Referências}

Almeida, António Campar de (2006). Paisagens: um património e um recurso. O Interior Raiano do Centro de Portugal: outras fronteiras, novos intercâmbios, Iberografias, 8. C:E.I., Guarda, pp. 31-42. 
Boura, M. Isabel (2006). As Aldeias Históricas de Portugal e as Rotas Culturais. O Interior Raiano do Centro de Portugal: outras fronteiras, novos intercâmbios, Iberografias, 8. C.E.I., Guarda, pp. 293-304.

Castro, Emanuel (2007). Análise Integrada da Paisagem da Raia Central Portuguesa: o território como recurso de desenvolvimento. Dissertação de Mestrado, Universidade de Coimbra, Coimbra.

Cunha, Lúcio (1995). Turismo e Desenvolvimento na Raia Central: a paisagem e o ambiente como recursos. Cadernos de Geografia, 14. I.E.G., F.L.U.C., Coimbra, pp. 129-138.

Cunha, Lúcio (2003). A montanha do centro português: espaço de refúgio, território marginal e recurso para o desenvolvimento local. In Lucília Caetano (cood.), Território, Ambiente e Trajectórias de Desenvolvimento, IV. C.E.G., F.L.U.C., Coimbra, pp. 35-62.

D’Abreu, A. Cancela; Correia, Teresa Pinto \& Oliveira, Rosário (2004). Contributos para a Identificação e Caracterização da Paisagem de Portugal Continental, Volume I. Colecção Estudos 10, D.G.O.T.D.U., Universidade de Évora.

Harner, John (2001). Place Identity and Copper Mining in Sonora. Annals of the Association of American Geographers, 91. México, pp. 660-680.

Roca, Zoran \& Oliveira, J. António (2005). A Paisagem como Elemento da Identidade e Recurso para o Desenvolvimento. Actas do X Congresso Ibérico de Geografia (CD-ROM). Évora. 